Check for updates

Cite this: RSC Adv., 2019, 9, 2386

Received 9th December 2018 Accepted 26th December 2018

DOI: $10.1039 / \mathrm{c} 8 \mathrm{ra10104c}$

rsc.li/rsc-advances

\section{Seed-assisted synthesis of TS-1 crystals containing Al with high catalytic performances in cyclohexanone ammoximation $\uparrow$}

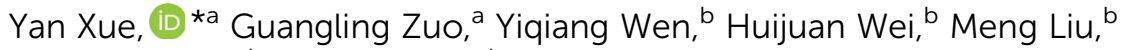 \\ Xiangyu Wang ${ }^{* \mathrm{~b}}$ and Baojun $\mathrm{Li}^{\mathrm{b}}$ \\ In this study, titanium silicalite (TS-1) crystals containing Al were synthesized using aluminosilicate MFI \\ zeolites as seeds in a tetrapropylammonium bromide (TPAB)-ethanolamine (EA) system. The TS-1 \\ containing Al possessed large size, large $L_{b}$ value and higher catalytic activity in cyclohexanone \\ ammoximation. Larger $L_{b}$ value would endow the TS-1 crystals with better mechanical strength and \\ erosion resistance. The introduction of an Al atom into the TS-1 crystals resulted in the production of \\ more acid sites and a bit strong Brönsted acid sites; these acid sites were more favorable to the catalytic \\ performances in cyclohexanone ammoximation.
}

\section{Introduction}

TS-1 molecular sieves with an MFI topology structure have received significant attention due to their active and selective catalytic performances in many selective oxidation reactions $\mathbf{1}^{\mathbf{1}}$ such as hydroxylation of aromatics, ${ }^{2,3}$ epoxidation of alkenes, ${ }^{4,5}$ ammoximation of ketone, ${ }^{6,7}$ and oxidation of bulky molecules. ${ }^{8}$ For TS-1 crystals, due to their diffusion limitation, the catalytic properties are dependent on the size of pores along the $b$-axis. ${ }^{9}$ The deactivation behavior of the TS- 1 catalyst is mainly caused by the deposits of coke on the micropores of zeolite. ${ }^{\mathbf{1 0 , 1 1}}$ Therefore, many approaches were explored to solve the problem. The first effective strategy was to enlarge the size of the $b$-axis micropores; then, hierarchical TS- 1 materials were synthesized using the mesopore template, ${ }^{\mathbf{1 2 - 1 4}}$ and hierarchical porous structures were constructed by treating the TS- 1 zeolite with organic bases. ${ }^{15-17}$ The second measure was to decrease the crystal size or reduce the $b$-axis depth; then, the diffusion limitations would be alleviated or even eliminated. The seedassisted syntheses of zeolites could induce rapid nucleation, shorten crystallization time and decrease the zeolite crystal size. ${ }^{\text {18-22 }}$ Furthermore, the b-oriented TS-1 zeolite membranes were synthesized by seed induction. ${ }^{23-25}$ However, in our previous study, after a $420 \mathrm{~h}$ continuous reaction for cyclohexanone ammoximation, many defects and caves were found on

${ }^{a}$ Biological and Chemical Engineering College, Nanyang Institute of Technology, 80 Changjiang Road, Nanyang 473004, China. E-mail: yanxue800@163.com

${ }^{b}$ Institute of Industrial Catalysis, School of Chemistry and Molecular Engineering, Zhengzhou University, 100 Science Road, Zhengzhou 450001, China. E-mail: xiangyuwang@zzu.edu.cn

$\uparrow$ Electronic supplementary information (ESI) available. See DOI: $10.1039 / \mathrm{c} 8 \mathrm{ra10104c}$ the surface of the big TS-1 particle, and some amorphous particles appeared on the outside of the TS- 1 particles. ${ }^{26}$ The dissolution of $\mathrm{Si}$ in the basic reaction medium led to a decrease in the catalytic stability. ${ }^{27}$ It is still our pursuit to prepare the rather thick TS-1 with high catalytic performances and higher stability.

Bifunctional zeolite catalysts have been employed in various processes in the petroleum refining and petrochemical industries because of their metallic and acid sites. ${ }^{28}$ Some metals, such as precious metals, ${ }^{29-31} \mathrm{Cd}^{2+},{ }^{32}$ and $\mathrm{Fe}^{2+},{ }^{33}$ incorporated into the TS- 1 skeletons have improved the catalytic activity of TS-1. It has been reported that TS-1 with $\mathrm{Al}^{3+}$ showed excellent activity and selectivity in the epoxidation of alkenes. ${ }^{34,35}$

The liquid-phase ammoximation of ketone over titanium zeolites as a highly efficient technology is attracting attention from industrial sectors. ${ }^{36,37}$ Cyclohexanone oxime is a key intermediate for the production of $\varepsilon$-caprolactam as a starting feed for the manufacture of nylon- 6 . The hierarchical porous structure was much more effective in improving the catalytic properties of TS- 1 zeolite for ketone ammoximation ${ }^{38,39}$ because the orifices on the surface of the catalysts could alleviate the diffusion limitations. Zhuo et $a .^{40}$ demonstrated the relation between the Lewis acid strength in titanosilicate catalyst and the selectivity of oximes; TS- 1 with stronger Lewis acidity provided better selectivity to oximes.

TS-1 with large size and high $L_{b}$ value would possess better mechanical strength and erosion resistance. In this study, largesized TS-1 crystals were prepared from an inorganic reactant system using different sized seeds to control the size (Scheme 1). Aluminosilicate and pure silicon zeolites were used as seeds to prepare the TS- 1 crystals and TS- 1 containing Al. The resources of the Ti and Si template used in this study were costeffective and suitable for industrialization production. The 


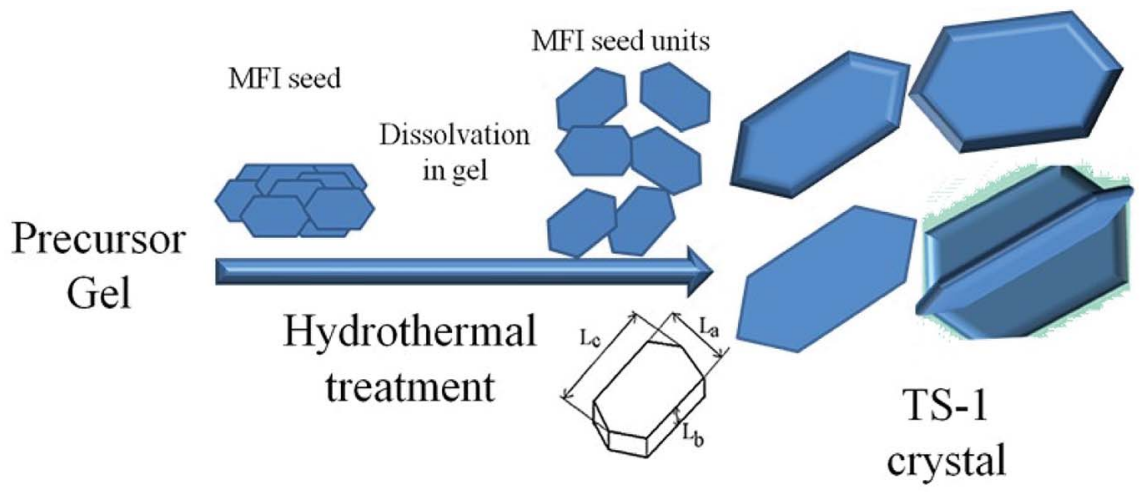

Scheme 1 The synthesis process of TS-1 by MFI seeds.

obtained zeolite particles were post-treated by alkaline solution and ТРАВ template to introduce mesopores into the zeolites; this eliminated the diffusion limitations of bulky molecules. The TS-1 using nano ZSM-5 seed exhibited big size, excellent catalytic activity and stability in cyclohexanone ammoximation.

\section{Experimental}

\subsection{Preparation of seeds}

Nano S-1 seed was synthesized with TEOS as the Si source. The molar composition of the precursors was set to 1.0TEOS : $0.20 \mathrm{TPAOH}: 20 \mathrm{H}_{2} \mathrm{O}$. The alcohol contents of the mixture were removed by heat treatment at $70{ }^{\circ} \mathrm{C}$ for $2 \mathrm{~h}$. The sol was aged at room temperature for $3 \mathrm{~h}$. Subsequently, the resulting sol was subjected to hydrothermal treatment at $170{ }^{\circ} \mathrm{C}$ for $48 \mathrm{~h}$. The solid product was filtered by centrifugation, washed with distilled water, and then dried at $60{ }^{\circ} \mathrm{C}$ for $12 \mathrm{~h}$ followed by calcination at $500^{\circ} \mathrm{C}$ for $6 \mathrm{~h}$. The micro S-1 seed was synthesized by the traditional hydrothermal treatment, and $\mathrm{NaOH}$ was used as a mineralizer. The molar composition of the precursors was $1.0 \mathrm{SiO}_{2}: 0.05 \mathrm{TPAB}: 0.20 \mathrm{NaOH}: 20 \mathrm{H}_{2} \mathrm{O}$.

The seeds of ZSM-5:Al(OH $)_{3}$ and silica aerogel are the $\mathrm{Al}$ and $\mathrm{Si}$ sources, and the molar composition of the mixture was $11.5 \mathrm{Na}_{2} \mathrm{O}: 100 \mathrm{SiO}_{2}: 3 \mathrm{Al}_{2} \mathrm{O}_{3}: 2750 \mathrm{H}_{2} \mathrm{O}$. The nanosized TS- 1 was added as seed. The solution was crystallized at $453 \mathrm{~K}$ for $48 \mathrm{~h}$. After washing, filtration and drying, nano ZSM-5 seeds were obtained. In addition, the micro ZSM-5 was obtained when no seed was added in the abovementioned solution.

\subsection{Synthesis}

TS-1 was prepared by hydrothermal synthesis using colloidal silica (31 wt\%) as the silicon source, tetrabutyl titanate (ТВOT) as the titanium source and TPAB as the template. Ethanolamine (EA) was used to adjust the $\mathrm{pH}$ value of the matrix gel. Isopropyl alcohol (IPA) was used as an additive. Molar composition of the gel was $\mathrm{SiO}_{2}: 0.02 \mathrm{TiO}_{2}: 0.5 \mathrm{IPA}: 0.1 \mathrm{TPAB}: 20 \mathrm{H}_{2} \mathrm{O}$. The process was similar to that reported in our early work. ${ }^{26}$ TS-1 was posttreated according to the report. ${ }^{26}$ The powders were modified with EA and TPAB, and $1.0 \mathrm{~g}$ of TS-1 raw powder was dispersed in EA and TPAB solution (molar composition of the solution was 1EA : $0.2 \mathrm{TPAB}: 50 \mathrm{H}_{2} \mathrm{O}, 12 \mathrm{~mL}$ ). Moreover, two types of zeolites of pure silicon and aluminosilicate with the MFI structure were selected as seeds: nano S-1 (n-S-1) and micro S-1 (m-S-1) and nano ZSM-5 (n-ZSM-5) and micro ZSM-5 (m-ZSM-5). The corresponding TS-1 prepared using the four seeds of n-S-1, m-S-1, nZSM-5 and m-ZSM- 5 were denoted as TS-1- $n(n=1-4)$ according to the abovementioned order. The solid product yields of TS-1 were $83.2 \%$ (TS-1-1), $85.3 \%$ (TS-1-2), $85.8 \%$ (TS-1-3), and $87.2 \%$ (TS-1-4).

\subsection{Characterization of TS-1}

$\mathrm{X}$-ray diffraction (XRD) patterns were obtained using an automatic powder diffractometer (Xpert PRO, PANalytical B. V.) in transmission geometry with $\mathrm{Cu} K \alpha 1(\lambda=1.5406 \AA)$. The relative crystallinity degree (RCD) was calculated by comparing the total intensity of five characteristic peaks of each sample with the intensity of TS-1-1 as $100 \%{ }^{39}$ The preparation and treatment conditions before measurement were uniform. The data were obtained for the same amount of sample using the same sample holder under the same instrumental conditions. Fourier transform infrared (FTIR) spectra were obtained using a Thermo Nicolet IR 380 Spectrometer in the range from 2000 to $400 \mathrm{~cm}^{-1}$. UV-vis spectra were obtained using an Agilent Cary 5000 spectrometer from 200 to $410 \mathrm{~nm}$. Nitrogen sorption measurements were performed at liquid nitrogen temperatures (77 K) using a Quantachrome NOVA 1000e surface area and pore size analyzer (Quantachrome Instrument, USA). Total specific surface area $\left(S_{\mathrm{BET}}\right)$ and pore volume were calculated according to the multi-point Brunauer-Emmett-Teller (BET) based on the adsorption branch of isotherm curves and the $t$-plot method. Pore size calculations were performed with the NLDFT method based on the desorption branch of the isotherm curves. ${ }^{41}$ Scanning electron microscopy (SEM) images were obtained with the uncoated powders immobilized on the sample holders with gold paste using the field emission microscope FEI Quanta 250 FEG at $20.00 \mathrm{kV}$. The particle size distribution was measured using the laser particle size analyzer RISE-2008. Ammonia temperature-programmed desorption (TPD) was carried out using a self-assembled fixed-bed reactor connected to a thermal conductivity detector (TCD). The samples were first outgassed by thermal treatment from ambient temperature to $600{ }^{\circ} \mathrm{C}$ at the heating rate of $10^{\circ} \mathrm{C} \mathrm{min}^{-1}$ in an Ar stream $\left(1.0 \mathrm{~mL} \mathrm{~s}^{-1}\right)$. 
After cooling at $150{ }^{\circ} \mathrm{C}$, the sample was saturated with a $\mathrm{NH}_{3}$ stream and consequently treated with an Ar stream $\left(1.0 \mathrm{~mL} \mathrm{~s}^{-1}\right)$ for $90 \mathrm{~min}$. Finally, the temperature was increased to $560{ }^{\circ} \mathrm{C}$ at the heating rate of $10{ }^{\circ} \mathrm{C} \min ^{-1}$, while determining the $\mathrm{NH}_{3}$ desorption. The FTIR spectra of pyridine adsorbed to the zeolite samples were acquired using a Thermo Nicolet IR 380 Spectrometer. The samples were prepared as thin self-supporting wafers of $15-20 \mathrm{mg} \mathrm{cm} \mathrm{cm}^{-2}$ size and placed inside a controlledenvironment IR transmission cell. Before pyridine adsorption, the catalyst wafer was heated to $600{ }^{\circ} \mathrm{C}$, and the cell was degassed for $3 \mathrm{~h}$. Subsequently, pyridine was introduced into the sample cell, and the cell was degassed and heated at $100{ }^{\circ} \mathrm{C}$ to remove physisorbed pyridine. The adsorbed pyridine was desorbed at $100{ }^{\circ} \mathrm{C}$ for $0.5 \mathrm{~h}$, and the in situ FTIR spectra were obtained. The particle size of TS- 1 was determined using the RISE-2008 laser particle size analyzer by dispersing $30 \mathrm{mg}$ samples in $2 \mathrm{~mL}$ water.

\subsection{Catalysis test}

Cyclohexanone ammoximation with TS-1 catalysts was performed in a three-necked flask (100 mL) equipped with a condenser and a magnetic stirrer. TS- 1 were employed as the catalyst, $\mathrm{H}_{2} \mathrm{O}_{2}$ aqueous solution $(8 \mathrm{wt} \%, 25.8 \mathrm{~mL}$ ) was used as the oxidant, $t$-butanol ( $85 \mathrm{wt} \%, 16.8 \mathrm{~mL}$ ) was used as the solvent and aqueous ammonia (25 wt\%, $13.2 \mathrm{~mL}$ ) was used as the ammonia source. In a typical run, cyclohexanone $(5.8 \mathrm{~g}), t$ butanol and catalyst were charged in a flask. The mixture was heated to $80{ }^{\circ} \mathrm{C}$. The reaction was then initiated by adding dilute aqueous $\mathrm{H}_{2} \mathrm{O}_{2}$ at a constant rate continuously using a micropump. The aqueous ammonia was added to the reaction solution in ten times. The molar ratio of precursors was as follows: $n \mathrm{NH}_{3} \mathrm{H}_{2} \mathrm{O}: n \mathrm{H}_{2} \mathrm{O}_{2}: n \mathrm{C}_{4} \mathrm{H}_{10} \mathrm{O}: n \mathrm{C}_{6} \mathrm{H}_{10} \mathrm{O}=3: 1.05: 2.6: 1$. After $3 \mathrm{~h}$, the product mixture was analyzed by GC-7890 gas chromatography equipped with a flame ionization detector (FID) and an OV-1701 capillary column $(30 \mathrm{~m} \times 0.32 \mathrm{~mm} \times 0.25 \mu \mathrm{m})$.

Mechanical strength test. The TS- 1 powders $(0.3 \mathrm{~g})$ were immersed in a $2 \mathrm{~mL} 0.5 \% \mathrm{NaOH}$ solution, which was stirred for $10 \mathrm{~min}$ at $80{ }^{\circ} \mathrm{C}$. The particle size distribution was measured. The TS-1 powders were dispersed in water for comparison.

\section{Results and discussion}

To illustrate the effects of seeds on the structure and morphology of TS-1, the XRD patterns, FTIR and UV-vis spectra were obtained. The TS- 1 synthesized from the inorganic reactants always had a big size. ${ }^{21}$

The crystal phase structures of TS- 1 were characterized by XRD patterns (Fig. 1). There were sharp peaks at $2 \theta=7.8^{\circ}, 8.8^{\circ}$, $23.0^{\circ}, 23.9^{\circ}$ and $24.4^{\circ}$, in accordance with the five characteristic peaks of MFI topology. ${ }^{19}$ All TS-1 possessed a typical MFI topology structure. The single diffraction peaks at $2 \theta=24.5^{\circ}$ and $29.5^{\circ}$ were ascribed to the Ti-atom entered into the zeolite framework. ${ }^{42}$ The RCD of TS-1-2 was highest. In the UV-vis spectra, the band around $210 \mathrm{~nm}$ was assigned to the framework Ti species (tetracoordinated Ti) (Fig. 2a). The bands at $260 \mathrm{~nm}$ and $330 \mathrm{~nm}$ were attributed to the amorphous $\mathrm{Ti}$ species (hexacoordinated $\mathrm{Ti}-\mathrm{O}-\mathrm{Ti}$ linkages and usually called non-framework $\mathrm{Ti}$ ) and $\mathrm{TiO}_{2}$ anatase-like oxide phases, respectively. ${ }^{43}$ The band at $230 \mathrm{~nm}$ was attributed to the isolated $\mathrm{Ti}$ species with less coordination number of oxygen (such as pentahedral Ti). The UV-vis spectra indicated that all TS-1 contained tetra-coordinated Ti in the framework (Fig. 2a). For TS-1-2 and TS-1-4 with big sized seeds, the band around $260 \mathrm{~nm}$ suggested more non-framework Ti in the TS-1 zeolites.

All TS-1 samples possessed three typical vibration absorption peaks at 550, 800 and $960 \mathrm{~cm}^{-1}$ (Fig. 2b). The bands at 550 and $800 \mathrm{~cm}^{-1}$ were assigned to the characteristic absorption of MFI topology. ${ }^{44}$ The peaks at $960 \mathrm{~cm}^{-1}$ were attributed to the stretching vibration of $\left[\mathrm{SiO}_{4}\right]$ units, strongly influenced by titanium ions at the neighbouring coordination sites. The TS- 1 crystals had a typical MFI topology structure and framework titanium. The intensities of the bands at $960 \mathrm{~cm}^{-1}$ were related to the strength of the $\mathrm{Si}-\mathrm{O}-\mathrm{Ti}$ bond and the content of framework Ti. The bands at $550 \mathrm{~cm}^{-1}$ were attributed to the characteristic of MFI topology corresponding to the pentasil vibration of double 5-membered rings. The level of Ti atoms incorporated into the framework was estimated by the band intensity ratio $I_{960} / I_{800} \cdot{ }^{45}$ Table 1 shows that the $I_{960} / I_{800}$ ratio of TS-1-4 synthesized by the m-ZSM-5 seed is higher than those of TS- 1 prepared with other seeds; this suggests more framework $\mathrm{Ti}$ content in the TS-1-4 with m-ZSM-5 seed.

$\mathrm{N}_{2}$-sorption isotherms were obtained to investigate the textural properties of TS-1 (Fig. 3a). There are hysteresis loops for TS-1 crystals, suggesting the mesoporous structure of TS-1 crystals; this may be due to the presence of mesopores between the crystals. The hierarchical micropores of $10 \mathrm{MR}$ and mesopores of TS-1 were observed in Fig. 3b. There was a slight difference in the isotherms and pore size distribution curves. There were three main peaks in the pore size distribution, and the most probable distributions of the mesopore sizes were $5.4 \mathrm{~nm}$ and $2.2-2.4 \mathrm{~nm}$ in the four crystals. Table 1 lists the textural properties and the $I_{960} / I_{800}$ ratio of these samples. There were little differences among the $S_{\mathrm{BET}}$ of the four TS- 1 samples, ranging between 421 and $458 \mathrm{~m}^{2} \mathrm{~g}^{-1}$. Because of the smaller crystal sizes, the $S_{\text {ext }}$ of TS-1-1 with n-S-1 seed was highest among those for the TS-1 samples.

The SEM images of the TS-1 synthesized with pure silicon and aluminosilicate molecular sieve seeds are shown in Fig. 4. All TS-1 with seeds exhibited the coffin-shaped morphologies. The coffin-shaped crystals were in two regularly encountered forms. ${ }^{4,47}$ The crystals were enclosed by two (010) planes, two (100) planes, and four (101) planes. The pores or caves were clearly observed in the SEM images of the TS-1 crystals (Fig. 4). Twin crystals were observed to grow along the vertical direction with the (010) planes in TS-1-1 crystals, which was randomly grown together sharing the (010) plane or along the vertical direction with the (010) planes. The size and shape of the crystals were controlled by seeds. For the same type of seeds, the TS- 1 sizes became larger with an increase in the seed size. The particle size of TS-1-2 was $2.32 \mu \mathrm{m}$ when seeds with a size of 1.95 $\mu \mathrm{m}$ were added, and the size of TS-1-1 was $0.85 \mu \mathrm{m}$ when the size of the seed was $0.25 \mu \mathrm{m}$. TS-1-3 and TS-1-4 with the sizes of 

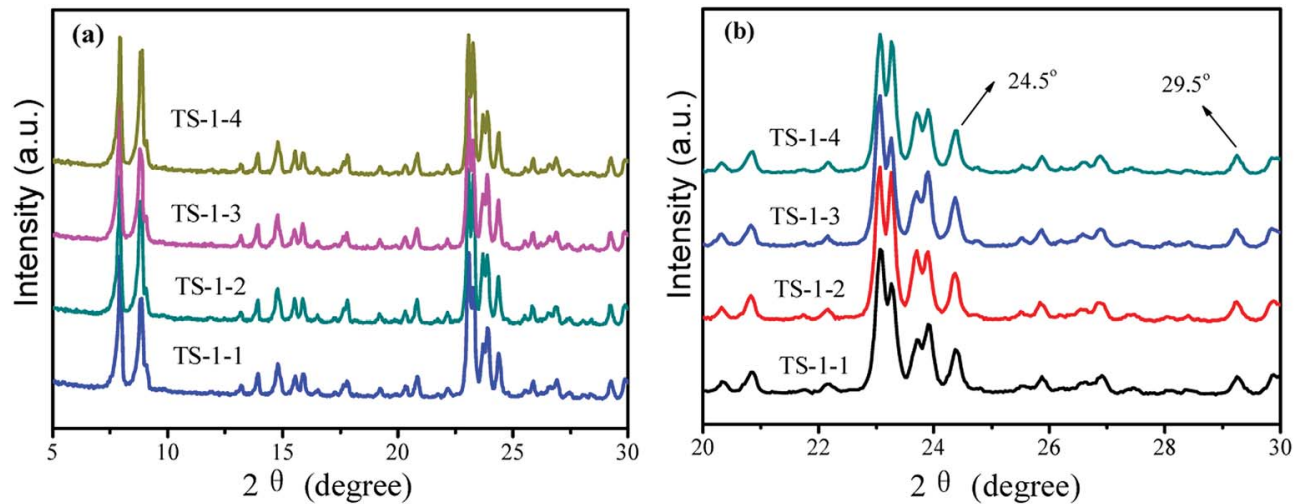

Fig. 1 (a) XRD patterns of TS-1 and (b) enlarged version in the range from 20 to 30 degree.

3.0 and $3.51 \mu \mathrm{m}$ were obtained by adding seeds with the sizes of 0.64 and $6.59 \mu \mathrm{m}$, respectively.

$L_{a}, L_{b}$ and $L_{c}$ represent the size of the MFI crystal in terms of width, depth and length, which are directly proportional to the crystal growth rates along the $a, b$ and $c$ axes, respectively (Scheme 1). The solid-phase transformation mechanism deemed the seed needed to dissolve first and functioned as a structure-directing agent in the crystallization process of TS1 crystals. The seed was firstly dissolved to form crystal nucleus which were attached on the gel. The gel was depolymerized and reorganized into aggregates of tiny primary units, which were restructured into zeolite nuclei and then grew into irregular objects accompanying a large number of crystal intergrowths. Lastly, a bulky particle was formed as the crystallization time extended. According to the growth mechanism, the dissolution rate of seeds is the key to the nucleation, and the morphology of crystal nucleus would affect the orientation of TS-1. The dissolution of seeds became the ratelimiting step in crystal growth, and the size of the TS- 1 crystals would reach minimum as the nuclei surface no longer increased at a relatively high amount of seed. ${ }^{48}$ The surface energies of the TS- 1 planes are different, and the crystal intergrowths are facing different directions; this results in different sizes and orientations.
Table 1 Physicochemical properties of TS-1

\begin{tabular}{|c|c|c|c|c|c|c|c|c|}
\hline \multirow[b]{2}{*}{ TS-1 } & \multirow[b]{2}{*}{ RCD (\%) } & \multirow[b]{2}{*}{$I_{960} / I_{800}$} & $S_{\text {total }}$ & $S_{\text {mic }}$ & $S_{\text {ext }}$ & $V_{\text {total }}$ & $V_{\text {mic }}$ & $V_{\text {ext }}$ \\
\hline & & & \multicolumn{2}{|c|}{$\mathrm{m}^{2} \mathrm{~g}^{-1}$} & & \multicolumn{2}{|c|}{$\mathrm{cm}^{3} \mathrm{~g}^{-1}$} & \\
\hline TS-1-1 & 100 & 1.5 & 431 & 393 & 38 & 0.24 & 0.17 & 0.07 \\
\hline TS-1-2 & 109 & 1.5 & 458 & 433 & 25 & 0.24 & 0.19 & 0.05 \\
\hline TS-1-3 & 98 & 1.5 & 421 & 394 & 27 & 0.21 & 0.17 & 0.04 \\
\hline TS-1-4 & 101 & 1.6 & 433 & 402 & 31 & 0.24 & 0.17 & 0.07 \\
\hline
\end{tabular}

There were some differences between the $\mathrm{Si} / \mathrm{Ti}$ ratio of the gel and that of the crystals (Table 2). The Si/Ti ratio of TS-1-2 was lower than that of other TS-1; this was ascribed to the dissolution of $\mathrm{Si}$ in the modification process. The Si/Ti ratios of TS-1-1 were higher because more Si from seed was introduced into the gel. The $\mathrm{Al}$ atom was introduced into the TS- 1 crystals with the aluminosilicate zeolite seeds. The Si was dissolved with difficulty and lost from TS- 1 crystals; this was attributed to the presence of $\mathrm{Al}$ atom in the TS- 1 crystals. The Si/Ti ratios for TS-13 and TS-1-4 were 53.4 and 59.7, whereas the Si/Al ratios were 181.9 and 240.0, respectively. TS-1-3 synthesized with the nZSM-5 seed exhibited lower ratio of $\mathrm{Si} / \mathrm{Al}$ and $\mathrm{Si} / \mathrm{Ti}$ than TS-1-4 synthesized with m-ZSM-5 seed; this was because the Al atom in small-sized seeds more easily entered into the TS- 1
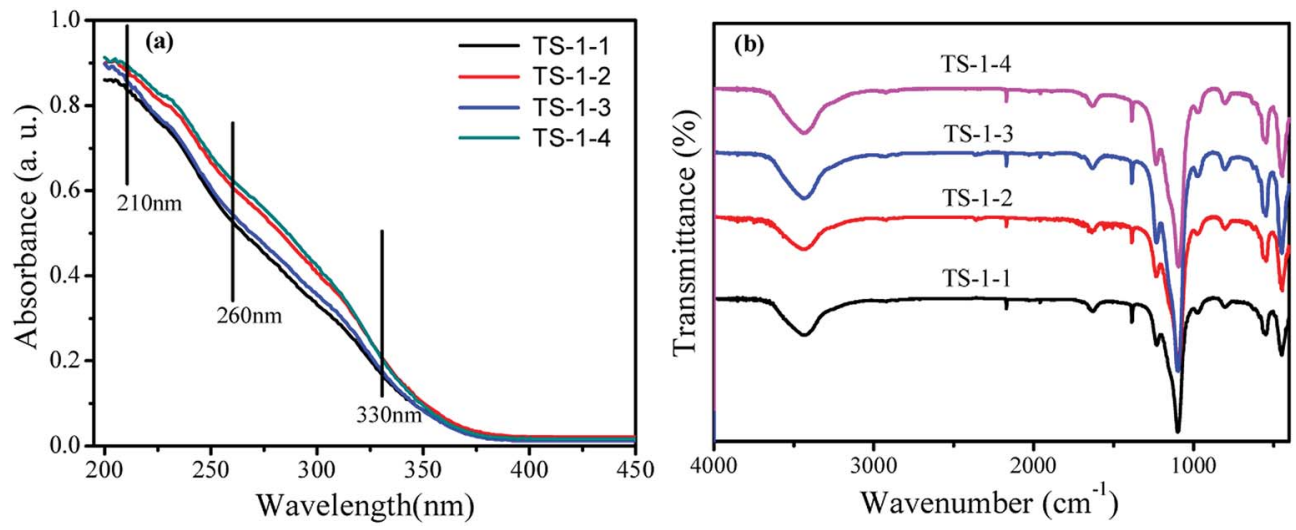

Fig. 2 (a) UV-vis and (b) FTIR spectra of TS-1. 

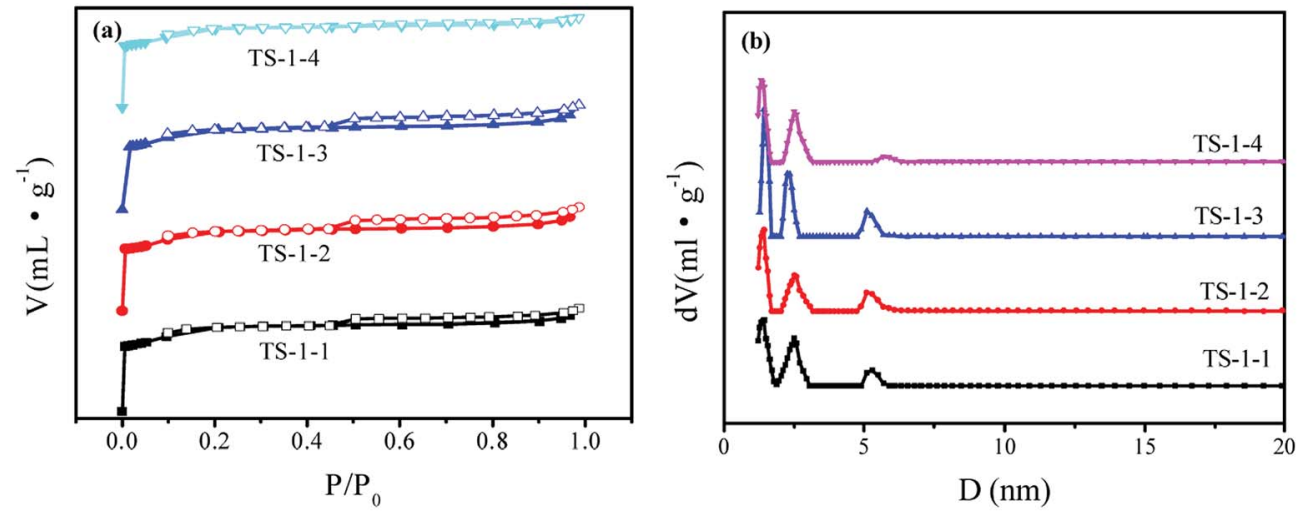

Fig. 3 (a) $\mathrm{N}_{2}$-adsorption (close symbol) and desorption (open symbol) isotherms and (b) pore size distribution obtained by the DFT method of TS-1 catalysts.

framework. The hybrid atoms in the skeleton of molecular sieve were close to saturation, the more $\mathrm{Al}$ with less Ti was incorporated into the framework; thus, the ratio of Si/Ti in TS-1-2 was lower than that in TS-1-3 and TS-1-4.

The catalytic performances of TS-1 in cyclohexanone ammoximation have been investigated (Fig. 5). TS-1-3 synthesized by nano-ZSM- 5 seeds exhibited the best catalytic performances. For TS-1 prepared with the same type of seeds, higher cyclohexanone conversion was obtained over the catalysts with a smaller size, and the catalytic activity was TS-1-4 > TS-1-1 > TS1-4 $>$ TS-1-2, which should be attributed to the incorporation of $\mathrm{Al}$ atoms and thinner size of TS- $1{ }^{48} \mathrm{TS}-1-2$, synthesized by m-S- 1 seed with a size of $2.32 \mu \mathrm{m}$, provided worse catalytic performances than TS-1-1 in cyclohexanone ammoximation due to its high Si/Ti ratio. TS-1 synthesized by aluminosilicate seeds presented large size and high $L_{b}$ value, but excellent catalytic activity. The possible reason was that the framework $\mathrm{Al}$ in the TS- 1 crystals resulted in acidity, which resulted in excellent catalytic performances. The size or $L_{b}$ value and $\mathrm{Al}$ in TS-1 were main reasons to cause the different catalytic performances: TS-
1-3 > TS-1-1 > TS-1-4 > TS-1-2. All TS-1 synthesized with the seed presented more excellent catalytic performances than TS-1 synthesized without adding seeds (Fig. S2 $\dagger$ ).

The b-channels and a-channels are interconnected with each other, and the c-direction is a tortuous pathway. The straight channel along the $b$-axis is the fast diffusion pathway; thus, the b-oriented MFI film is mostly pursued. The molar conversion of cyclohexanone per milligram $\mathrm{Ti}\left(\mathrm{mmol} \mathrm{mg}{ }^{-1} \mathrm{Ti}\right)$ and the $L_{b}$ value were calculated to explore the change tendency of cyclohexanone conversion with the variation of $L_{b}$ ratio in Table 2. For the TS- 1 with the two types of seeds, the bigger $L_{b}$ value provided lower conversion of cyclohexanone. The molar conversion of cyclohexanone per milligram Ti of TS1-3 with the seeds of n-ZSM- 5 was higher than that of TS-1-1 and TS-1-2; this was ascribed to the implantation of $\mathrm{Al}$ in theTS- 1 catalysts. The thinner $L_{b}$ is conducive to the better catalytic performance. However, TS-1 catalysts with $\mathrm{Al}$ atoms in crystals exhibited higher $L_{b}$ values and improved catalytic performance in cyclohexanone ammoximation due to their acidity.
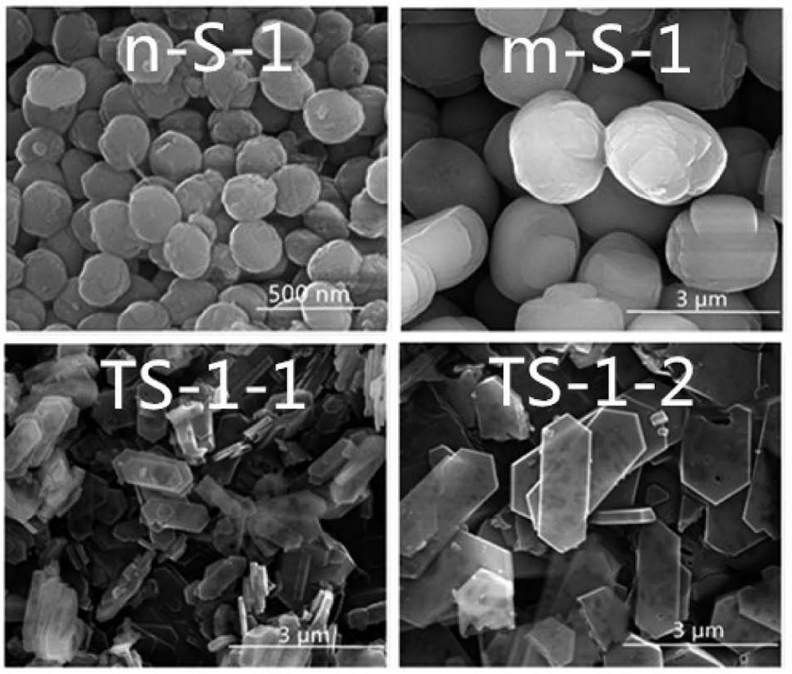
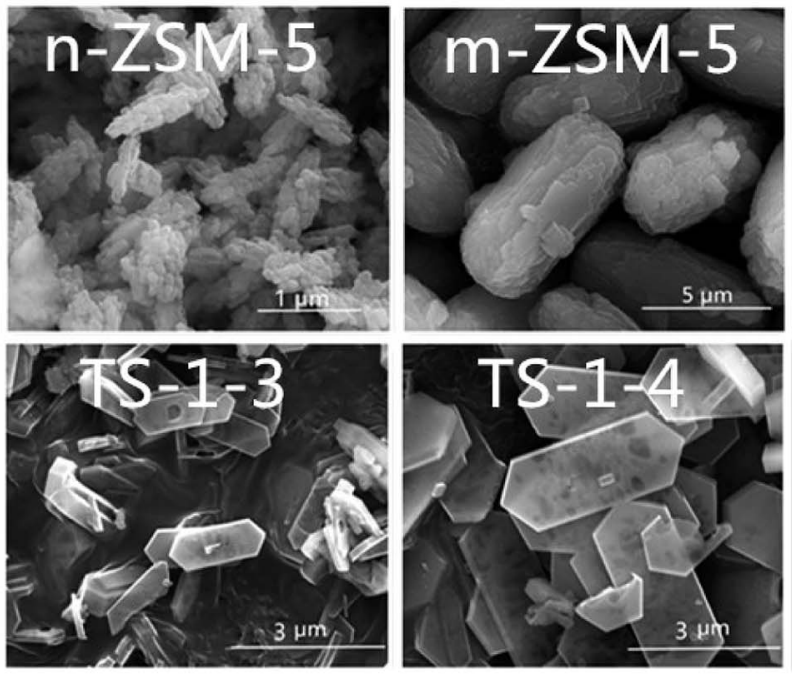

Fig. 4 SEM images of seeds and the corresponding TS-1. 
Table 2 Size information and elemental analysis of the TS-1 crystals

\begin{tabular}{|c|c|c|c|c|c|c|c|}
\hline TS-1 & Seed type & \multicolumn{2}{|c|}{ Average size $(\mu \mathrm{m})$} & $\mathrm{Si} / \mathrm{Ti}$ & $\mathrm{Si} / \mathrm{Al}$ & $\mathrm{TPD}\left(\mathrm{mmol} \mathrm{g}^{-1}\right)$ & $\begin{array}{l}\text { Molar conversion } \\
\text { of cyclohexanone per mg } \mathrm{Ti}\end{array}$ \\
\hline TS-1-2 & Micro S-1 (m-S-1) & 2.32 & 0.18 & 36.0 & - & - & 0.127 \\
\hline TS-1-3 & Nano ZSM-5 (n-ZSM-5) & 3.00 & 0.23 & 53.4 & 181.9 & 0.11 & 0.146 \\
\hline TS-1-4 & Micro ZSM-5 (m-ZSM-5) & 3.51 & 0.34 & 59.7 & 240.0 & 0.06 & 0.117 \\
\hline
\end{tabular}

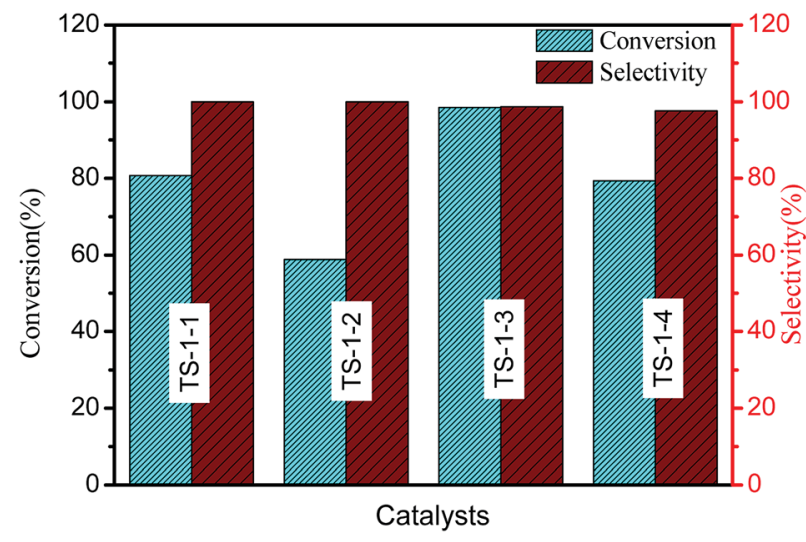

Fig. 5 Conversion of cyclohexanone and selectivity of cyclohexanone oximes with TS-1 as catalysts in cyclohexanone ammoximation. Reaction conditions: $5.8 \mathrm{~g}$ of cyclohexanone with $0.40 \mathrm{~g}$ of catalyst at $80^{\circ} \mathrm{C}$ for $3 \mathrm{~h}$.

The FTIR spectra of pyridine adsorbed on TS- 1 zeolites after evacuation are shown in Fig. 6. The bands at $1490 \mathrm{~cm}^{-1}$ characteristic of both Brönsted acid sites at $1540 \mathrm{~cm}^{-1}$ and Lewis acid sites at $1450 \mathrm{~cm}^{-1}$ were assigned to Lewis acid sites; ${ }^{49}$ the bands at $1446 \mathrm{~cm}^{-1}$ associated with hydrogen-bonded pyridine were strong, and they overlapped the peak at $1450 \mathrm{~cm}^{-1}$ attributed to TS- 1 zeolites. TS- 1 zeolites synthesized by pure

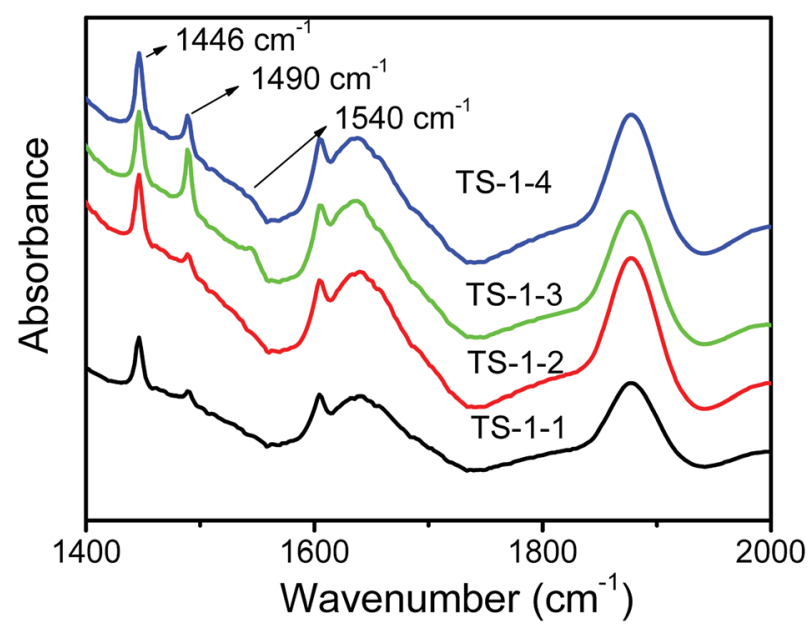

Fig. 6 FTIR spectra of pyridine adsorption of TS-1 zeolites synthesized by aluminosilicate seeds. silicon seeds was free of Brönsted acid sites, as shown in Fig. 6; thus, the bands at $1490 \mathrm{~cm}^{-1}$ could infer that small amounts of Lewis acid sites existed in TS- 1 zeolites synthesized by pure silicon seeds. Lewis acid and a small amount of Brönsted acid sites coexisted in TS-1 zeolites synthesized by aluminosilicate seeds, and the peak of Brönsted acid in TS-1-3 with the lowest ratio of $\mathrm{Si} / \mathrm{Al}$ was the biggest among the three TS- 1 zeolites, and there was a slightly weaker peak of Brönsted acid in TS-1-4 (Fig. S1 $\dagger$ ). Generally, $\mathrm{Al}$ atoms from seeds caused the generation of Brönsted acid.

The acidity of TS-1 zeolites synthesized by S-1 and ZSM-5 seeds was measured by $\mathrm{NH}_{3}$-TPD, as shown in Table 2. TS-1 synthesized with pure silica seeds exhibits a negligible $\mathrm{NH}_{3}$ adsorption capacity, whereas TS-1 synthesized with aluminosilicate seeds demonstrates increased $\mathrm{NH}_{3}$ adsorption capacity with the increasing aluminum content. These indicated that both the acid sites and the acid amounts were enhanced by introducing $\mathrm{Al}$ during the preparation.

The average particle size of TS-1-4 was highest and that of TS1-1 was smallest. The particle size obtained by the SEM images was the size of $L_{c}$, and the size obtained by the laser particle size analyzer was the size of $L_{c}, L_{b}$ or $L_{a}$; thus, the size obtained by the SEM images was different from the size obtained by the laser particle size analyzer. The size of TS- 1 decreased after treatment with $\mathrm{NaOH}$ solution; this implied that the crystals were corroded in a basic environment. The particle size (Fig. 7) of TS-

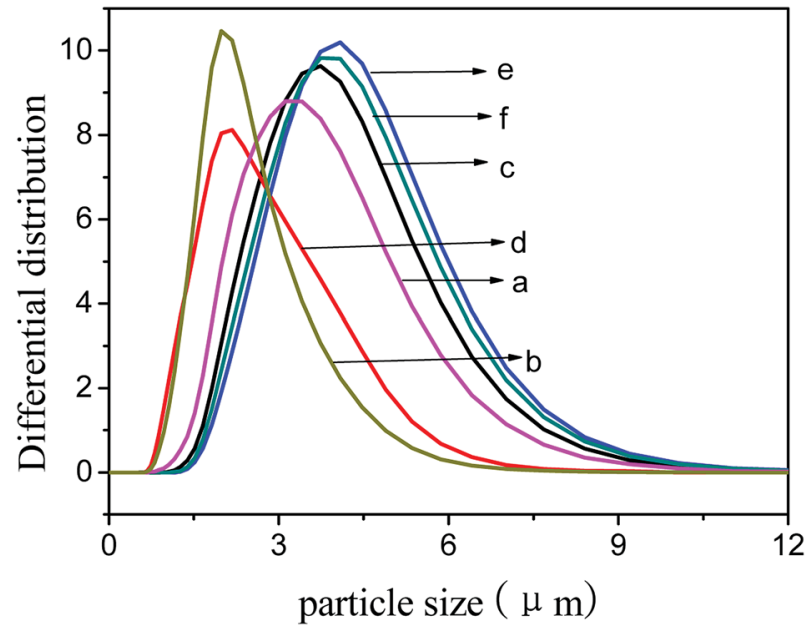

Fig. 7 Particle size distribution of TS-1 zeolites synthesized by aluminosilicate seeds (a) TS-1-2, (b) TS-1-3, (c) TS-1-4, and destructive TS-1 (d) TS-1-2, (e) TS-1-3, and (f) TS-1-4 treated by $\mathrm{NaOH}$. 
1-4 showed little change after treatment with $\mathrm{NaOH}$ solution and that of TS-1-2 and TS-1-3 showed big change after the treatment. The crystals with a large $L_{b}$ value would exhibit better mechanical strength and erosion resistance.

\section{Conclusions}

In conclusion, large-sized TS- 1 crystals containing $\mathrm{Al}$ were synthesized with aluminosilicate zeolite as a seed in the TPABEA system. TS- 1 crystals with different sizes and orientations were obtained by different kinds of seeds. With the decreasing size of the same type of seeds, the size of TS- 1 became smaller. The depth of TS-1 zeolites affects their catalytic performances; TS-1 synthesized by seeds with $\mathrm{Al}$ atoms presented bigger $L_{b}$ value and more improved catalytic performances than that synthesized with pure silica seeds. TS- 1 crystals with a large $L_{b}$ value would exhibit better mechanical strength and erosion resistance. The as-synthesized TS-1 obtained using nano ZSM-5 seed exhibited large $b$-axis depth and high catalytic performances in cyclohexanone ammoximation because the $\mathrm{Al}$ atom in seeds was introduced into the TS- 1 crystals and brought more acid active site and strong Brönsted acid. This study is of great significance for the design of high-performance industrial catalysts.

\section{Conflicts of interest}

There are no conflicts to declare.

\section{Acknowledgements}

Financial supports received from the National Natural Science Foundation of China (no. U1204203 and 21401168), the Innovation Fund for Elitists of Henan Province, China (no. 0221001200) and the Outstanding Young Teacher Development Fund of Zhengzhou University (no. 1421316037) are acknowledged.

\section{References}

1 L. A. Truter, D. M. Perez Ferrandez, J. C. Schouten and T. A. Nijhuis, TS-1 coated microreactor for selective oxidations, Appl. Catal., A, 2015, 490, 139-145.

2 X. Gao, J. An, J. Gu, L. Li and Y. Li, A green template-assisted synthesis of hierarchical TS-1 with excellent catalytic activity and recyclability for the oxidation of 2,3,6-trimethylphenol, Microporous Mesoporous Mater., 2017, 239, 381-389.

3 H. Jiang, X. Jiang, F. She, Y. Wang, W. Xing and R. Chen, Insights into membrane fouling of a side-stream ceramic membrane reactor for phenol hydroxylation over ultrafine TS-1, Chem. Eng. J., 2014, 239, 373-380.

4 G. Xiong, D. Hu, Z. Guo, Q. Meng and L. Liu, An efficient titanium silicalite-1 catalyst for propylene epoxidation synthesized by a combination of aerosol-assisted hydrothermal synthesis and recrystallization, Microporous Mesoporous Mater., 2018, 268, 93-99.
5 J. H. Zhang, M. B. Yue, X. N. Wang and D. Qin, Synthesis of nanosized TS-1 zeolites through solid transformation method with unprecedented low usage of tetrapropylammonium hydroxide, Microporous Mesoporous Mater., 2015, 217, 96-101.

$6 \mathrm{~J}$. Ding and P. Wu, Selective synthesis of dimethyl ketone oxime through ammoximation over Ti-MOR catalyst, Appl. Catal., A, 2014, 488, 86-95.

7 Z. Zhuo, L. Wang, X. Zhang, L. Wu, Y. Liu and M. He, Insights into the key to highly selective synthesis of oxime via ammoximation over titanosilicates, J. Catal., 2015, 329, 107-118.

8 A. Silvestre-Albero, A. Grau-Atienza, E. Serrano, J. GarcíaMartínez and J. Silvestre-Albero, Desilication of TS-1 zeolite for the oxidation of bulky molecules, Chem. Commun., 2014, 44, 35-39.

9 J. Tekla, K. A. Tarach, Z. Olejniczak, V. Girman and K. GóraMarek, Effective hierarchization of TS-1 and its catalytic performance in cyclohexene epoxidation, Microporous Mesoporous Mater., 2016, 233, 16-25.

$10 \mathrm{X}$. Zhang, Y. Wang and F. Xin, Coke deposition and characterization on titanium silicalite-1 catalyst in cyclohexanone ammoximation, Appl. Catal., A, 2006, 307(2), 222-230.

11 Y. Wang, S. Zhang, Y. Zhao and M. Lin, The mechanism of catalyst deactivation and by-product formation in acetone ammoximation catalyzed by hollow titanium silicalite, $J$. Mol. Catal. A: Chem., 2014, 385, 1-6.

12 K. Cho, K. Na, J. Kim, O. Terasaki and R. Ryoo, Zeolite Synthesis Using Hierarchical Structure-Directing Surfactants: Retaining Porous Structure of Initial Synthesis Gel and Precursors, Chem. Mater., 2012, 24(14), 2733-2738.

13 Q. Du, Y. Guo, H. Duan, H. Li, Y. Chen and H. Liu, Synthesis of hierarchical TS-1 zeolite via a novel three-step crystallization method and its excellent catalytic performance in oxidative desulfurization, Fuel, 2017, 188, 232-238.

14 Y. Fang and H. Hu, Mesoporous TS-1: nanocasting synthesis with CMK-3 as template and its performance in catalytic oxidation of aromatic thiophene, Chem. Commun., 2007, 8, 817-820.

15 Y. Xue, Y. Wen, H. Wei, M. Liu, X. Huang, X. Ye and B. Li, Hollow TS-1 mesocrystals: hydrothermal construction and high catalytic performances in cyclohexanone ammoximation, RSC Adv., 2015, 5(64), 51563-51569.

16 G. Wu, Z. Lin, L. Li, L. Zhang, Y. Hong, W. Wang and X. Yan, Experiments and kinetics of the epoxidation of allyl chloride with $\mathrm{H}_{2} \mathrm{O}_{2}$ over organic base treated TS-1 catalysts, Chem. Eng. J., 2017, 320, 1-10.

17 B. Wang, X. Peng, W. Zhang, M. Lin, B. Zhu, W. Liao and X. Shu, Hierarchical TS-1 synthesized via the dissolutionrecrystallization process: Influence of ammonium salts, Chem. Commun., 2017, 101, 26-30.

18 M. Liu, Z. Chang, H. Wei, B. Li, X. Wang and Y. Wen, Lowcost synthesis of size-controlled TS-1 by using suspended seeds: From screening to scale-up, Appl. Catal., A, 2016, 525, 59-67. 
19 T. Xue, H. Liu, Y. Wang, H. Wu, P. Wu and M. He, Seedinduced synthesis of small-crystal TS-1 using ammonia as alkali source, Chin. J. Catal., 2015, 36(11), 1928-1935.

20 F. Xu, M. Dong, W. Y. Gou, et al., Rapid Tuning of ZSM-5 Crystal Size by Using Polyethylene Glycol or Colloidal Silicalite-1 Seed, Microporous Mesoporous Mater., 2012, 163, 192-200.

21 Y. Zuo, M. Liu, T. Zhang, et al., Enhanced Catalytic Performance of Titanium Silicalite-1 in Tuning the Crystal Size in the Range 1200-200 nm in a Tetrapropylammonium Bromide System, ChemCatChem, 2015, 7, 2660-2668.

22 Y. Zuo, X. S. Wang and X. W. Guo, Synthesis of Titanium Silicalite-1 with Small Crystal Size by Using Mother Liquid of Titanium Silicalite-1 as Seed, Ind. Eng. Chem. Res., 2011, 50(14), 8485-8491.

23 F. Qiu, X. Wang, X. Zhang, H. Liu, S. Liu and K. L. Yeung, Preparation and properties of TS-1 zeolite and film using Sil-1 nanoparticles as seeds, Chem. Eng. J., 2009, 147(2-3), 316-322.

24 M. H. Zhu, L. Li, L. Chen, Y. X. Liao, W. J. Ding, Z. J. Feng, Z. Wan, N. Hu, X. S. Chen and H. Kita, Preparation of TS-1 zeolite membrane from dilute precursor synthesis solution, Microporous Mesoporous Mater., 2019, 273, 212218.

25 X. Jiang, Z. Zhuang and F. Xin, Hydrothermal crystallization of b-oriented TS-1 films on PVAc-modified glass, Microporous Mesoporous Mater., 2013, 172, 141-145.

26 Y. Xue, Y. L. Xie, H. J. Wei, et al., Improving the performance of TS-1 catalysts for continuous cyclohexanone ammoximation through controlment of active species distribution, New J. Chem., 2014, 38, 4229-4234.

27 M. Zhou, M. Grahn, H. Zhou, A. Holmgren and J. Hedlund, The facile assembly of nanocrystals by optimizing humidity, Chem. Commun., 2014, 50(91), 14261-14264.

28 G. Wu, F. Hei, N. Zhang, N. Guan, L. Li and W. Grünert, Oxidative dehydrogenation of propane with nitrous oxide over Fe-ZSM-5 prepared by grafting: characterization and performance, Appl. Catal., A, 2013, 468, 230-239.

29 S. B. Shin, D. W. Lee and D. Chadwick, The effects of impregnation of precious metals on the catalytic activity of titanium silicate (TS-1) in epoxidation of propene using hydrogen peroxide, J. Mol. Catal. A: Chem., 2016, 423, 478488.

30 A. Prieto, M. Palomino, U. Díaz and A. Corma, One-pot twostep process for direct propylene oxide production catalyzed by bi-functional Pd(Au)@TS-1 materials, Appl. Catal., A, 2016, 523, 73-84.

31 T. Ayvalı, L. Ye, S. Wu, B. T. W. Lo, C. Huang, B. Yu, G. Cibin, A. I. Kirkland, C. Tang, A. A. Bagabas and S. C. Edman Tsang, Mononuclear gold species anchored on TS-1 framework as catalyst precursor for selective epoxidation of propylene, $J$. Catal., 2018, 367, 229-233.

$32 \mathrm{M}$. Wu, H. Song, F. Wang and L. Chou, The positive role of cadmium in TS-1 catalyst for butadiene epoxidation, $J$. Mol. Catal. A: Chem., 2013, 379, 207-212.
$33 \mathrm{Q}$. Wu, H. Wang and C. Yi, Preparation of photo-Fenton heterogeneous catalyst (Fe-TS-1 zeolite) and its application in typical azo dye decoloration, J. Photochem. Photobiol., A, 2018, 356, 138-149.

$34 \mathrm{H}$. Li, Q. Lei, X. Zhang and J. Suo, One-pot synthesis of ethylene glycol and its mono-methyl ether from ethylene using Al-TS-1 catalyst, Chem. Commun., 2009, 10(14), 19361939.

35 R. Van Grieken, D. P. Serrano, J. A. Melero and A. García, Effect of the solvent in the liquid phase rearrangement of 1,2-epoxyoctane over Al-MCM-41 and Al-TS-1 catalysts, $J$. Mol. Catal. A: Chem., 2004, 222(1-2), 167-174.

36 L. Xu, J. Ding, Y. Yang and P. Wu, Distinctions of hydroxylamine formation and decomposition in cyclohexanone ammoximation over microporous titanosilicates, J. Catal., 2014, 309, 1-10.

37 Y. Hu, C. Dong, T. Wang and G. Luo, Cyclohexanone ammoximation over TS-1 catalyst without organic solvent in a microreaction system, Chem. Eng. Sci., 2018, 187, 60-66.

38 A. Bhaumik, M. P. Kapoor and S. Inagaki, Ammoximation of ketones catalyzed by titanium-containing ethane bridged hybrid mesoporous silsesquioxane, Chem. Commun., 2003, (4), 470-471.

39 A. Bhaumik, S. Samanta and N. K. Mal, Highly active disordered extra large pore titanium silicate, Microporous Mesoporous Mater., 2004, 68, 29-35.

40 Z. X. Zhuo, L. Z. Wu, L. Wang, et al., Lewis acidic strength controlled highly selective synthesis of oxime via liquidphase ammoximation over titanosilicates, RSC Adv., 2014, 4, 55685-55688.

41 A. Thangaraj, R. Kumar, S. P. Mirajkar, et al., Catalytic properties of crystalline titanium silicalites I. Synthesis and characterization of titanium-rich zeolites with MFl structure, J. Catal., 1991, 130, 1-8.

42 G. Ricchiardi, A. Damin, S. Bordiga, et al., Vibrational Structure of Titanium Silicate Catalysts. A Spectroscopic and Theoretical Study, J. Am. Chem. Soc., 2001, 123, 1140911419.

43 Y. Zuo, M. Liu, T. Zhang, et al., Role of pentahedrally coordinated titanium in titanium silicalite-1 in propene epoxidation, $R S C A d v$., 2015, 5, 17897-17904.

44 D. Lesthaeghe, P. Vansteenkiste, T. Verstraelen, A. Ghysels, C. E. A. Kirschhock, J. A. Martens, V. V. Speybroeck and M. Waroquier, MFI Fingerprint: How Pentasil-Induced IR Bands Shift during Zeolite Nanogrowth, J. Phys. Chem. C, 2008, 112, 9186-9191.

45 W. B. Fan, R. G. Duan, T. Yokoi, et al., Synthesis, Crystallization Mechanism and Catalytic Properties of Tirich TS-1 Free of Extraframework Ti Species, J. Am. Chem. Soc., 2008, 130, 10150-10164.

46 G. Zeng, C. B. Chen, D. B. Li, et al., Exposure of (001) planes and (011) planes in MFI zeolite, CrystEngComm, 2013, 15, 3521-3524.

47 M. B. J. Roeffaers, R. Ameloot, M. Baruah, et al., Morphology of Large ZSM-5 Crystals Unraveled by Fluorescence Microscopy, J. Am. Chem. Soc., 2008, 130, 5763-5772. 
48 H. Kath, R. Gläser and J. Weitkamp, Beckmann Rearrangement of Cyclohexanone Oxime on MFI-Type Zeolites, Chem. Eng. Technol., 2001, 24, 150-153.
49 P. Li, G. Q. Liu, H. L. Wu, et al., Postsynthesis and Selective Oxidation Properties of Nanosized Sn-Beta Zeolite, J. Phys. Chem. C, 2011, 115, 3663-3670. 